WellBeing International

WBI Studies Repository

$2-2004$

\title{
A Model of Animal Selfhood: Expanding Interactionist Possibilities
}

Leslie Irvine

University of Colorado Boulder

Follow this and additional works at: https://www.wellbeingintlstudiesrepository.org/acwp_habr

Part of the Animal Studies Commons, Ethics and Political Philosophy Commons, and the Other Anthropology Commons

\section{Recommended Citation}

Irvine, L. (2004). A model of animal selfhood: Expanding interactionist possibilities. Symbolic Interaction, 27(1), 3-21.

This material is brought to you for free and open access by WellBeing International. It has been accepted for inclusion by an authorized administrator of the WBI Studies Repository. For more information, please contact wbisr-info@wellbeingintl.org.

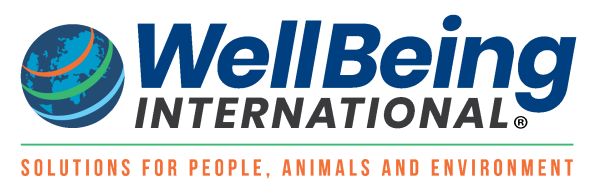




\title{
A Model of Animal Selfhood: Expanding Interactionist Possibilities
}

\author{
Leslie Irvine \\ University of Colorado, Boulder
}

\begin{abstract}
Interaction between people and companion animals provides the basis for a model of the self that does not depend on spoken language. Drawing on ethnographic research in an animal shelter as well as interviews and autoethnography, this article argues that interaction between people and animals contributes to human selfhood. In order for animals to contribute to selfhood in the ways that they do, they must be subjective others and not just the objects of anthropomorphic projection. Several dimensions of subjectivity appear among dogs and cats, constituting a "core" self consisting of agency, coherence, affectivity, and history. Conceptualizing selfhood in this way offers critical access to animals' subjective presence and adds to existing interactionist research on relationships between people and animals.
\end{abstract}

The notion that animals, like people, have selves is controversial for sociology. The field has defined its subject matter as that which is uniquely human. Along with culture, rationality, and language, the self is one of the entities for which animals purportedly lack the tools. The word tool is important here, for tool use and, later, tool making long served to distinguish humans from (and portray them as superior to) other animals. When Jane Goodall (1990) observed the chimpanzee David Greybeard not only using a tool but also making one, her observation called for redefining the existing boundary between humans and animals. If some animals have the ability to make and use various physical tools, perhaps they also possess the conceptual tools required for selfhood. In other words, if we humans were wrong about tool use among animals, there are likely other things we have underestimated and overlooked, such as their capacity for selfhood. Perhaps the boundary of self-consciousness that has long divided humans from animals is also illusory. If so, then how can sociologists, in particular, interactionists, study animal selfhood? What might we gain from and contribute to the task?

Scholars from a range of disciplines have repeatedly challenged the once-distinct boundary between human and nonhuman animals by showing that the latter can feel emotions (e.g., Bekoff 2000; Darwin [1872] 1998; Goodall 1990; Masson 1997; Masson and McCarthy 1995; Tabor 1983; Thomas 1993, 1994, 2000) and communicate with symbols (e.g., Patterson and Linden 1981; Pepperberg 1991). In humans, emotions and symbol use indicate the presence of capacities that constitute selfhood. In interactionist sociology, Sanders $(1990,1991,1993,1999)$ draws on everyday interaction between people and dogs to illustrate the construction of personhood and the sharing of basic emotions and intentions. Likewise, Alger and Alger (1997) examine attributions of selfhood among cat owners. Following Sanders, they observed cats engaged in taking the role of the others, defining situations, choosing courses of action, and having memories of past events. In addition, Alger and Alger's research in a cat shelter reveals that cats have culture, in that they transmit behaviors socially, as well as instinctually, through symbolic interaction (1999, 2003; see also Bonner 1980; Dawkins 1998).

The interactionist paradigm is well suited to the study of animal selfhood, and applying it expands the notion of what it means to be social. Using interactionism in this way requires moving beyond Mead's 
([1934] 1962) language-driven model of selfhood. For Mead, spoken language constituted the social psychological barrier between humans and nonhumans because it enables humans to understand and communicate the symbols for self, such as our names and the names of objects. Mead acknowledged that animals have their own social arrangements but claimed that their interaction involves a "conversation of gestures." This term denotes primitive, instinctual acts, such as when a dog growls at another who threatens to steal his bone or a cat hisses at a rival. Mead considered the conversation of gestures insignificant because it allegedly has only one meaning. As Hewitt (2000:9) explains, "[I]n no sense does either [animal] 'decide' or 'make up its mind' to act in a certain way." In this perspective, the behavior of animals may be goal directed in that it aims at getting food, a mate, or defending territory, but it lacks the negotiated meaning that characterizes human behavior. According to Mead, animals, lacking the capacity to use significant symbols, were incapable of having any meaningful social behavior. From Mead's perspective, "the animal has no mind, no thought, and hence there is no meaning [in animal behavior] in the significant or self-conscious sense" (Strauss 1964:168).

In making spoken language the key to what distinguishes humans from other animals, Mead (and, consequently, social psychology) established two states of consciousness: one for those who could converse about it and another, lesser form for those who could not. Mead thus advanced the anthropocentric, rationalist tradition of Descartes, whose claim I think, therefore I am required the ability to talk about thinking. The pitfalls in Mead's view are numerous, and other scholars have reviewed them in detail (see Arluke and Sanders 1996; Myers 1998; Sanders 1999; Sanders and Arluke 1993). My intention here is to offer a model of animal selfhood that expands the possibilities of empirical interactionist research. In doing this, I build on previous work by Sanders and Alger and Alger that examines how we come to know animals as conscious, purposeful partners in interaction. Whereas Sanders and Alger and Alger have demonstrated animals' capacity for intersubjectivity, I examine the capacities that animals must have in order to achieve this shared experience. My conclusions apply only to companion animals, by which I mean the dogs and cats with whom so many of us share our homes and our daily lives. ${ }^{1}$ Although some of my arguments might well apply to other animals, I have studied only dogs and cats. I leave it to other researchers to incorporate other species.

Before proceeding, I want to anticipate an objection and emphasize that I have taken care to avoid overanthropomorphizing. Note that I said "overanthropomorphizing," for we cannot entirely escape our human perspective. As Shapiro (1997) points out, this perspective is not something we take only when we try to understand animals. Rather,

all understanding is anthropomorphic (from anthropo, meaning "man" and morphe, "form" or "shape") for it is partly shaped by the human investigator as subject. However, since this is a perspective or "bias" inherent in all experience, it is not an occasional attributional error to which we are particularly prone when we cross species' lines. It is a condition of science which prevents it from reaching certainty and, therefore, from supporting a positivistic philosophy. (P. 294)

Those who use the term anthropomorphism usually intend to discredit someone's claims about animals by suggesting they are sentimental and inaccurate projections. However, in describing animals, our choices are not limited simply to the "unconstrained use of anthropomorphism on one hand and the total elimination of anthropomorphism on the other" (Bekoff 2002:49-50). A middle ground involves informed, systematic interaction with and observation of animals known as "critical" or "interpretive" anthropomorphism (Burghardt 1998; Fisher 1991; see also Crist 1999; Mitchell, Thompson, and Miles 1997; Sanders 1999). Critical anthropomorphism aims to do for the understanding of animal life what Verstehn (Weber 1949) tries to capture in human life, which is to understand the meanings that people give to their actions. Verstehn involves placing oneself in the position of another person to see what 
purpose his or her actions might have, or, more accurately, to see what that person believes his or her actions will accomplish. Critical anthropomorphism tries to do the same for the experiences of nonhuman animals. Bekoff (2002:48) refers to it as "humanizing animals with care," for it respects the "natural history, perceptual and learning capabilities, physiology, nervous system, and previous individual history" of animals (Burghardt 1998:72). In what follows, I strive to recognize the differences between animals and people while exploring what we share in common.

\section{METHODS}

The evidence presented here draws on several sources of data collected and analyzed through continuous, emergent inductive techniques (see Becker and Geer 1960; Charmaz 1983; Glaser 1978; Glaser and Strauss 1967; Stewart 1998; Strauss and Corbin 1997). I conducted more than three hundred hours of research in what Adler and Adler (1987) call a "complete membership role" at a humane society that I refer to as "the Shelter." This private, nonprofit organization offers adoptions, veterinary services, humane education, dog training, and cat behavior consultations and serves as the headquarters for the city's animal control services and welfare investigations. In 1998 I began working as one of the Shelter's volunteers. I have served in many volunteer roles; this article draws chiefly but not exclusively on that of adoption counselor. This position involves introducing people to animals whom they are considering for adoption, providing information about behavior and training, and answering questions. Moreover, it involves determining whether the animal and the person will be a good "match." As an adoption counselor, I became curious about people's interactions with animals in the adoption area and began taking notes. I recorded how long they looked at particular animals, whether they adopted an animal that day or just visited, and what, if anything, they said to the animals or to the people with them. I also took extensive notes about the interaction that occurred when a person (or persons) and a particular animal were introduced.

My volunteer service on what I call the Adoption Mobile, a thirty-foot recreational vehicle that serves as a traveling branch of the Shelter, produced an additional one hundred fifty hours of observation. Five days a week, a volunteer and a staff member take a selection of adoptable cats, rabbits, rodents, and a dog to various sites throughout the county. The locations include shopping centers, libraries, and local festivals. On board, people can adopt animals, make donations, and obtain answers to their questions about animal care and behavior or the Shelter's services. The Adoption Mobile spends four hours at a given site, and an average of one hundred people visit during this time. The work entails intense interaction with the public, and I took notes about the interaction in a small notebook while on site.

In spring 1999 I began developing another source of data through autoethnography. Because the term suggests several different meanings, let me be clear about how I use it. ${ }^{2}$ In particular, I want to distinguish it from autobiographical research. The sense of the term as I intend it originated with Hayano (1979), who used it to refer to the study of a group with which one is involved (in Hayano's case, professional card players). In this sense, autoethnography offers an "insider's" view that can only come through immersion in and intimate knowledge of the group's interaction. The approach dates back at least to Charles Horton Cooley ([1902] 1964), who described a version of "sympathetic introspection." More recent practitioners include Denzin (1989), Ellis (1991, 1997, 1998), Rambo Ronai (1992, 1996), and Sanders (1999). In all these works the researcher puts himself or herself into the inquiry, but the result is much more than a report on the ethnographer.

I began the autoethnographic phase of this research by taking notes about my interactions with my own companion cats. I had lived with cats all my adult life, but I stopped taking our lives together for granted and became a participant-observer of our daily routines. Then, in summer 1999, I adopted a dog from the Shelter. As the cats and I adjusted to life with him, I wrote it all down. I examined my autoethnographic 
notes and those from the Shelter regularly, searching for emergent themes and patterns. Over repeated readings, one idea - the way in which animals communicate their personalities, emotions, preferences, and knowledge to people-came through clearly. To explore this idea further, I began interviewing those who adopted and surrendered animals. The Shelter generously helped me to recruit interviewees by attaching an information and consent form to their adoption paperwork for one month in 2001. I conducted forty semistructured interviews that focused on how people made decisions to adopt, how they had chosen particular animals, and how everyday life and activities with the animal unfolded after adoption.

\section{RETHINKING THE SELF}

Observations of the interactions between people and animals in the adoption areas revealed three themes. The first is seeking relationships with the animals. A steady stream of people, most having no intention to adopt, came to visit the animals. Some even came regularly, to visit long-term Shelter residents. They often came in pairs or groups, making the visit a social event. Their interaction with animals was not limited to looking at them but also involved talking to them and about them. Everyone wanted to touch the animals, know their names and their stories, and, whenever possible, hold and play with them outside of their kennels or cages. Moreover, many people who had browsed the Shelter's Web site wanted to meet the animals whom they had seen in thumbnail photos. In other words, they did not simply want to know that the animals existed; they wanted to interact with them face-to-face. In other words, they wanted relationships with the animals.

The second theme has to do with concern for animals' well-being. Shelter clients wanted to learn the animals' histories and, in the case of adoption, provide what he or she needed. This concern appeared in phrases I heard frequently, such as "I feel so sorry for them" and "I wish I could take them all home." People were genuinely concerned when animals seemed afraid or were obviously recovering from an operation or injury. For example, the Shelter's male dogs routinely wear E-collars (Elizabethan collars) after they are neutered to prevent them from licking at their sutures. They wear these for only a few days, but people consistently ask what happened to the "poor dog" with the cone around his head. Similarly, when longhaired cats arrive with their coats badly matted, the only solution is a full-body shave, usually leaving fur on the head, paws, and tail. Shelter staff and volunteers grow so accustomed to the barrage of questions about what happened to the "poor kitty" that we often add notes explaining the "bad hair day" on the cats' kennel cards.

The third theme involves increasing complexity of interaction. In the adoption areas, I found that people who had had animals previously, some for most of their lives, interacted with a wider range of animals and did not fuss as much over the puppies and kittens. Moreover, with repeated or sustained interaction, people began to explore more facets of the animal's character and capabilities. For instance, a first visit might involve strolling past the kennels and cages, just looking. Then, when a particular animal captured someone's attention, the person might begin talking to the animal, perhaps squatting down to get closer. When this offered an opportunity for an animal to display some unique trait, such as playfulness or attentiveness, the person then engaged the animal further. This, in turn, revealed additional aspects of the animal's "personality" and continued in a reciprocal process, allowing the person to discover more about the animal as interaction grew more complex, albeit within the confines of the kennels. Moreover, animals served as "social facilitators," sparking conversations among visitors and thus encouraging the use of interactional skills with other people as well (see Messent 1983; Sanders 1999, 2000).

The interaction in the adoption areas thus suggests that people seek relationships with animals, express concern for their well-being, and engage in increasingly complex behaviors with them. These three themes, I argue, have one thing in common: they point in the direction of the self. More specifically, they 
are behaviors or activities that manifest goals of the self (see Myers 1998). For instance, we know from Mead and others that the self emerges through relationships. Once the self has developed, it can exist without relationships, so that the person in solitary confinement continues to have a sense of self. However, relationships allow us to develop a mutual history that is simultaneously a history of the self (see Irvine 1999).

If we can agree that relationships are essential for the self, it would be important to increase the skills that make relationships possible. Maintaining relationships requires the use of the interactional skills that foster relationships in the first place. One of the signs that a relationship is "good for" the self is that it exercises and improves our interactional skills. Good relationships stretch our interactional abilities by requiring us to see things in new ways. Good relationships offer "new information-incongruities, interruptions of expectations, challenges-in the context of familiar otherness" (Myers 1998:78). They challenge our interactional skills just enough and consequently increase our abilities to have relationships. As with physical exercise, we build "muscle" that equips us for further challenges. Eventually, the exercise itself becomes intrinsically rewarding. Moreover, concern for the well-being of others, expressed through an interest in their needs, ensures the continuity that provides the relationships on which the self depends.

In sum, the structure of interaction between people and animals (seeking relationships with animals, demonstrating concern for their well-being, and engaging in increasingly complex interaction) revealed that animals mean something for the experience of selfhood. The question that arises has to do with how they "mean something." Related to this, how do animals differ from the other "objects" in our environment that contribute to our sense of self?

\section{Sensing Subjectivity}

The key, I argue, is the subjective presence of the Other. The interaction must seem to have a source, and we must see the Other as having a mind, beliefs, and desires, just as we do. This not only confirms the Other's sense of self to us; it also confirms our own. How do we sense an Other's subjective presence? With people, we can rely on self-reports. However, these reveal more about the norms of selfreports than about anything else. Self-reports reveal the influence of what people know to be good, desirable, acceptable depictions of the self. They reveal a self-digested in consciousness and shaped by language. They indicate how people talk and think about the self, not how they experience it. A stronger objection is that, even with other people, we simply do not rely on language first or foremost for information about selfhood. As Goffman (1959) wrote, only part of the self is conveyed through "impressions given." Other aspects appear through "impressions given off."

Relying on language eliminates a considerable amount of interaction as a source of information that contributes to selfhood. Moreover, it restricts the significant interactants to other people. If we can agree that factors beyond spoken language matter for the creation of the self, then animals can participate in the process. In the model of the self that I am using, in order for animals to do so, they must themselves be subjective Others. How can we sense their subjective presence? As with other people, we cannot observe subjectivity directly. We perceive it indirectly, during interaction. To illustrate how this is so, I turn to a model of self that originates in William James's ([1890] 1950, [1892] 1961) efforts to gain access to the "I," or the subjective sense of self. Along the way, James distinguished four facets that underlie and make us aware of subjectivity. Others have since refined these into a set of basic self-experiences that manifest themselves in infancy, before the acquisition of language (see Myers 1998; Stern 1985). Therefore, the case can be made for the presence of these experiences among animals, who have the same structures of the brain, nervous system, musculature, and memory. Whereas human development 
takes us into a stage of language acquisition that adds to these basic experiences, the experiences themselves are preverbal. The four self-experiences consist of

1. a sense of agency, meaning that you are the author of your actions and movements and not the author of the actions and movements of others;

2. a sense of coherence, meaning that you understand yourself as a physical whole that is the locus of agency;

3. a sense of affectivity, meaning patterned qualities of feelings that are associated with other experiences of the self; and

4. a sense of self-history, meaning that you maintain some degree of continuity, even while changing.

Human beings attain these four senses of self through interaction with others, beginning at birth. They not only underlie our own senses of subjective experience, but, as we shall see, they also form the basis for distinguishing self from Other. Combined, these four senses compose a "core" self that is considered necessary for normal psychological functioning (Stern 1985:71). The absence of one of them manifests itself in psychosis and other pathologies. Granted, there are additional senses of self, many of which require the acquisition of language, but the four I draw attention to here are prior to and essential for additional senses. Here, I offer illustrative examples of how these aspects of core self are manifested among dogs and cats.

\section{Agency}

In sociology, the term "agency" is used (and misused) in many ways. ${ }^{3}$ I use it to refer to the capacity for self-willed action. Agency implies subjectivity, in that an agentic being, by definition, has desires, wishes, and intentions, along with a sense of having those things. In other words, it is the actor's awareness of having desires or wishes that is an element of selfhood, not simply having them. Agency also implies having control over one's own actions (i.e., I can sit when I decide to, and if you push me into a chair, that is something different) and awareness of the felt consequences of those actions. For example, my intention to sit brings the felt consequence of sitting. Fortunately, the connection occurs mostly outside of consciousness, for evaluating every action in these terms would be tedious indeed.

Several indicators of a sense of agency appear in the first months of life (Stern 1985). Examples include reaching for objects and hand-to-mouth skills. At about four months, infants begin to use visual information to shape the fingers to accommodate objects of particular sizes. Since agency does not depend on verbal ability, it is therefore feasible among other species. Some of the best examples of animals' agency come from the arena of dog training, even at the beginner's level. As Sanders (1999) explains, the main thing that trainers teach dogs is to exercise self-control-and they use precisely this term. Self-control implies that the dog has a sense that he or she can initiate action, since in order to control one's self one must first have a sense of will or volition. At the Shelter, I saw frequent examples of this when I worked with staff members to make undersocialized dogs more adoptable. A typical case involved a young, mixed-breed dog who jumped up on the gate of his kennel and barked wildly for attention whenever anyone came near, making most potential adopters think twice. The key to modifying the dog's behavior was to change his understanding of the cause of the rewards he receives. Changing his understanding in this way highlights the nonverbal capacity to distinguish self from Other.

A dog who jumps up on his kennel and barks receives two kinds of rewards. To the extent that the behavior is self-directed (i.e., aimed at releasing energy), it is constantly rewarding. However, to the extent that it is directed at others, as an attempt to gain their attention, there is only a probabilistic chance that it will be rewarded. Many people will avoid such a dog-as was the case with the dog in this 
example. As long as the reward of attention depends on others, it will be unpredictable. The dog does not control that reward. The only thing he controls (or should) is his behavior. We had to make the dog aware of this and show him how to increase the probability of rewards from others. To do so, we removed him from the adoption area for a few days to reduce the foot traffic past his kennel. We scheduled regular exercise to reduce his need for the jumping. Most important, we stopped reinforcing his bad behavior. We paid attention to him only when he was quiet and had all four paws on the floor. If he stood up on his hind legs or barked, we moved away from his kennel. Because he had released some of his pent-up energy through exercise, the reward of attention quickly became a higher priority. Moreover, because attention depended on others, he soon learned to control himself to get it. This subtle act of behavior modification helped the dog to distinguish self from Other by distinguishing different reinforcement schedules. Infants develop this ability as early as three months of age; the same probably holds for other highly social animals, with the same implications for discriminating between self and Other.

One day, as a staff member and I discussed our work with the above-mentioned dog, she said, "We have to get him to be able to show people that he'll be worth it." It occurred to me that although our explicit task was to help him to learn basic canine manners, our larger, albeit implicit, goal was to enable him to demonstrate to people that he had something underneath, or other than, the problem behaviors. In other words, we had to help him to develop the control over his own behavior that would show people that he had-or was-a self.

\section{Coherence}

If agency provides a sense of self versus Other, then coherence provides the boundaries of the self. We acknowledge coherence when "we say of some others that they seem to 'have their act together,' or of our own Self, that some particular line of endeavor is 'very much part of me"' (Bruner and Kalmar 1998:311). Coherence gives agency somewhere to "live." Several indicators of coherence do not rely on language, making their presence likely in nonhuman animals.

Infancy research indicates that the capacity to recognize distinct others, such as primary caregivers, becomes available as early as two or three months of age. Animals, too, can recognize distinct others. At the Shelter, volunteers who regularly work with certain animals for weeks or even months find that these animals begin to recognize them. More relevant for the discussion of coherence is how animals are able to understand that parts of people belong together. For example, at the Shelter's veterinary clinic, I had regular contact with a dog who required several surgeries and diagnostic tests. I often held him while a technician drew blood, and I sat with him as he woke up after his first surgery. When he recovered and went into the adoption area, other volunteers spent more time with him, but whenever he saw me, he brightened up. One day, when an E-collar obscured his vision, I approached him from behind as he stood next to another volunteer who was conversing with a third person. As I passed an adjoining hall, I greeted someone in that direction. As I did, the dog's tail wagged and he turned as if to confirm that the physical form matched the voice. Although some might dismiss this as simply a conditioned response (that is, my voice had been programmed into his behavioral repertoire), critical anthropomorphism calls for a more contextualized and sympathetic understanding. Familiarity with dogs' behavior, and with this dog's behavior, leads me "to discount perspectives that rely on instinctual or rigidly behavioristic explanations" (Arluke and Sanders 1996:43; see also Alger and Alger 2003:47).

Animals indicate the capacity for coherence in the act of hiding, which requires a sense of self as an object to conceal from others. According to Sanders (1999:137), hiding "shows an awareness that the 'embodied self' is in danger and that concealment is in order" (see also Allen and Bekoff 1997). Cats, having evolved as skilled predators, relied on the ability to hide in order to hunt. Those mechanisms did not disappear with domestication. As one guardian explains: "Anyone who has lived around cats has 
seen this: they hide, they watch, and they attack. They also have very strong notions of when it's okay for them to be seen and any cat-person knows that cats have got to have hiding places." Alger and Alger (2003:58) found that cats can adapt their hiding into games of peek-a-boo and hide and seek.

Coherence has generated the cultural practice of naming animals, which "underscores the animal's particularity-the sense of uniqueness between subjective self and other" (Myers 1998:71; see also Alger and Alger 2003; Masson and McCarthy 1995; Phillips 1994). One of the things people do on adoption is name-or rename - their animals. Some guardians have a name in mind already; others take some time to decide on one, emphasizing the extent to which the name has to suit the animal. The act of changing an animal's name reflects the degree to which an animal's identity emerges through interaction. For instance, a dog who arrived with the name Rowdy became Sadie in her new home, indicating vastly different perceptions of her demeanor.

Phillips, in her study of researchers' conduct toward laboratory animals, finds that naming reflects individuality and coherence:

[I]n giving an animal a name and using that name to talk to and about the creature, we interactively construct a narrative about an individual with unique characteristics, situated in a particular historical setting, and we endow that narrative with a coherent meaning. (1994:121)

Proper names, Phillips writes, "are linked to the social emergence of personality, which engenders a matrix of ideas and behaviors unique to one individual" (p. 123). Scientists do not name laboratory animals because they see them as parts, rather than whole, coherent beings. They are sources of cells or tissue or "containers" for responses and reactions. Because naming acknowledges coherence, lab animals must remain nameless if researchers are to use them in the ways that they do. ${ }^{4}$

\section{Affectivity}

Another dimension of the core self that makes animals' subjectivity available to us is their capacity for emotions. In interviews, guardians reported two ways that they read the emotions of their dogs and cats, and these correspond to two dimensions of feeling.

The first dimension encompasses what are called "categorical affects." Most of the time when we think of "emotions," we think of discrete categories of feelings, such as sadness, happiness, fear, anger, or shame. Anyone who lives around animals has seen manifestations of various categorical affects. For example, I have seen cats display grief. Two of my cats, a male and a female, formed a very close bond. They slept together, ate and played together, and groomed each other. When the male had to be euthanized, his companion went through a distinct period of grieving. Indeed, her sadness started before her friend died, when he gradually became withdrawn and disinterested. When the male was gone, the female searched their favorite places for him and stopped eating for a few days. She did not become "herself" again until we moved into a new house. Granted, the behaviors I characterize as feline grief may not be the same as human grief; this is irrelevant. However, I do know that she behaved differently after her friend's death than she behaves when she is sunning herself (a state I would call happiness or contentedness) or inspecting my belongings after I return at the end of a day (curiosity). Along the same lines, Alger and Alger (2003) describe displays of happiness, affection, frustration, irritability, depression, empathy, and jealousy among sheltered cats.

A second dimension of emotions comprises "vitality affects." These are ways of feeling, rather than discrete emotions, and they give the behavior of human and nonhuman animals much of its texture. Bruner and Kalmar (1998:311) point out that vitality affects "signal the 'feel' of a life-mood, pace, zest, 
weariness, or whatever." Long before I knew the term "vitality affects," I knew about them. This is so for most of us, for the perception of vitality affects occurs early in infancy. When my niece, Amanda, now a teenager, was very young, I entertained her by making my index and middle fingers into the "legs" of a character whose "body" was my hand. This character could make her laugh by walking up her arm, but we both had more fun when it danced the can-can. This little "person"-it did seem to have what it takes for personhood-could act as if exhausted or take a jaunty walk.

Instances such as these work because we can read vitality affects. ${ }^{5}$ We know when the character portrayed by fingers "feels" chipper or bedraggled, and it has nothing to do with facial expressions, for there are no faces to do the expressing. This is an important way in which the comparison applies to animals. Animals' limited ability to change their facial expressions (relative to humans) makes their expressions an unreliable means by which we can infer their emotional states. The vitality affects of animals inform us more than their facial expressions do. In our interaction with animals, we read vitality affects and perceive certain individuals as "sweet," "mellow," "hyper," and so on. These are characteristics of individual animals, that is, the core self, rather than the expressions of particular emotions. I other words, when we describe an animal (or a person), we usually include some reference to vitality affects. We might describe someone as "a happy person," but what we mean by that has more to do with vitality affects than with a discrete emotional state. We do the same with animals. Vitality affects are important vehicles of the core self. A woman who described her dog as "sweet," for example, was referring to the dog's overall calmness and submissive tendencies. Likewise, a couple who called their cat a "character" used the phrase as shorthand for his confidence and curiosity, the combination of which often sent him rushing in where more angelic cats would not dare to tread.

\section{Self-History}

Self-history, or continuity, makes interactions into relationships. As Stern (1985:90) writes, "a sense of a core self would be ephemeral if there were no continuity of experience." The capacity that makes continuity possible is memory. Events, objects, others, and emotions gain their meaning and are preserved in memory, in the context of relationships. There are many different modalities of memory, some of which begin to operate very early. The memory required for self-history is preverbal, and several aspects of it appear in animals. ${ }^{6}$ Anyone who has ever taken a dog or a cat to a veterinarian knows that animals remember places. The cat who loves affection at home now hisses and scratches the vet's offending hand. Skeptics might say that the animal "just smells fear," thereby is missing the reaction as instinctual. However, even if it were "only" instinct, the consistent ability to register a particular emotion in a particular setting nevertheless implies a sense of continuity. Others have also documented animals' "place memory" (Alger and Alger 2003; Lerman 1996; Sanders 1999). Indeed, Shapiro (1990, 1997) suggests that the lives of dogs are oriented in terms of place, rather than time, as ours are. Feline examples abound in the work of Alger and Alger $(1997,2003)$. For instance, they recount how one of their own cats always went to a certain throw rug when she wanted to play, and one of their interviewees described how her cat associated their home's radiator with receiving affection (1997:78). In the Algers's research in the cat shelter, they observed that the cats designated certain places such as cage tops and beds as "not just comfortable places for sleeping, but also safe places to relax, to find intimacy with others, and to explore their need for affection" (2003:110). The sheltered cats learned to define these areas in the same terms, suggesting a coherent system of memory created through symbolic interaction.

A behaviorist would characterize these examples not as memory but as simple conditioned responses. In behaviorist terms, the animal who feels fear at a veterinary clinic or pleasure in another setting merely perceives an impulse associated with previous positive or negative reinforcement. To be sure, in light of Occam's razor, which favors behavioristic accounts, cognitive explanations seem implausible. However, just as it is unwise to attribute simple behaviors to complex mental processes, it is equally unwise to 
dismiss, ignore, or deny the possibility that some behaviors may be best explained in cognitive terms. The question is which behaviors are best explained this way, and the answer is far from clear.

Allen and Bekoff (1997:56-62) make a distinction that is useful in this context. They distinguish between behavior that is "stimulus bound," meaning an invariable (or nearly so) response to external stimulus, and behavior that is "stimulus free," or motivated by internal factors. When external factors are seen to dominate internal factors, behaviorist explanations are preferred. However, in many instances, behaviorist conclusions have been drawn from research that ignores or disregards internal factors. For example, many laboratory studies of allegedly stimulus-bound behaviors must modify conditions so that animals will be sufficiently motivated to perform according to behaviorist expectations. This is especially the case in experiments involving food rewards, in which researchers must keep animals motivated to eat even when internal responses perceive satiation. Laboratory researchers introduce protocols that interfere with metabolism in order for the animals to eat beyond satiety. In such cases, stimulus-bound conclusions are drawn from behaviors that under normal circumstances would be stimulus-free. Drawing on an example closer to home, two of my cats regularly sleep on a fleece blanket. It is not stretching the point to say that they find this blanket comforting. This comfort has been to some degree conditioned. Nevertheless, if I were to produce the same blanket while the cats were being examined at the vet's office, I can confidently say that neither cat would respond with kneading and napping. The behavioral explanation becomes inadequate in contexts that involve various inputs. A more complex explanation is needed, and the possibility of memory seems a reasonable alternative.

Animals may have no sense of today, tomorrow, and next week, but they do remember what happened to them in the past. They do not need the sense of past, present, and future that gives purpose to human lives. Consequently, their memory skills differ from ours, but they differ in degree rather than kind. In interaction with humans, animals' memories give humans a sense of the animal as having a concrete history.

In sum, we know the selves of animals in much the same way we know the selves of other people. Two things occur simultaneously. First, animals' subjectivity becomes available to us because elements of a core self become visible through interaction. Granted, the kinds of selves that animals have, or at least those that are visible to humans, are less sophisticated in many ways than human selves are, but the core elements are nonetheless the same. Second, we know the selves of animals because, as this core self becomes present to us, it confirms our own sense of subjectivity. Certain animals' selves, like certain people's selves, mesh with ours in ways that feel comfortable. The feeling is one of being able to "be ourselves," and it occurs with animals through the same basic processes as it occurs with other people.

\section{CONCLUSION}

The structure of people's interaction with adoptable animals (seeking relationships with them, demonstrating concern for their well-being, and engaging in increasingly complex interaction with them) suggests that animals contribute something to the experience of human selfhood. Understanding how they "mean something" requires examining further interactions, such as those that take place when an animal is part of a human home and family. This type of interaction reveals aspects of the animal's subjective presence. Subjectivity, in turn, accounts for what makes animals different from the other factors that contribute to our sense of self.

Evidence of subjectivity appears in the core dimensions of self. If we think of self as a system of experiences having the features of agency, coherence, affectivity, and history, then our interaction with others will reflect our perception of those features. For example, agency evokes agency. When I perceive it in an animal or another person, doing so confirms my own sense of agency. My interaction with the 
Other will manifest my expectation and recognition of that agency, along with my response to it. The assumption that the Other can initiate action gives our interaction a particular structure. The Other and I will act toward each other as two beings who are authors of their own conduct. Moreover, when I assume agentic qualities in an Other, I assume the Other's subjectivity. At the same time, I understand myself as agentic, albeit without dwelling on the matter. A helpful example comes from Myers's (1998) study of children and animals. He observed instances in which a child provoked an animal to react, such as when one chased a pigeon and reported, "I made it fly." As Myers explains, "[T]hese children focused on their own agency, but agency means something only with an animate other. In flying away, the action of the pigeon confirms the child's own agency in a way that an inanimate thing cannot" (p. 82).

In the case of coherence, an Other's recognition of me as an embodied, bounded being confirms my own sense of myself in that way. When I come home, for example, the dogs and cats recognize me and greet me in ways that they would not extend to someone else. Their doing so confirms my sense of myself, although this occurs unconsciously, for I seldom pause to check that I am indeed "me." The animals' (and other people's) consistent recognition of me makes this unnecessary. In the case of affectivity, people who live with animals regularly respond to the qualities and intensity of animals' emotions. Moreover, our recognition of animals' affectivity usually occurs in particular contexts, which provides another avenue to confirming our own experience. For example, Sanders describes his experience with his dogs:

The joy my dogs communicate to me offers an important lesson. When I see the happiness they derive from a walk in the woods, a meal provided at the usual time, the warmth of a body to press against on a cold evening, I realize that the basic and immediate pleasures are the most important and should be treasured. (Quoted in Bekoff 2000:128)

Finally, animals' capacity for memory, which enables self-history, confirms our own sense of history, albeit in a more limited way than the confirmation we experience with other people. With other people, we can create a shared narrative, which is an undeniably more complex account of mutual experience. However, animals use bodies, gestures, preferences, and habits to demonstrate that they share a history with us. For instance, for the past thirteen years, I have slept with my grey, female cat, Pusskin, at my side. Regardless of what she is doing when I go to bed, she joins me. She and I nestle close in a way that I share with none of the other cats. After thirteen years, this way of sleeping together defines our relationship. I cannot imagine sleeping without the warmth and weight of her beside me, and I dread the time when she will no longer be there. Whatever reasons she has for seeking me out at night, I cannot be certain. What I can say is that she remembers where she likes to sleep, and she and I have built a history because she does so.

In this article, I have worked inductively, moving from observations to a model of selfhood instead of beginning with a particular notion of the self. However, the result is an incomplete picture of selfhood for animals, as it would be for humans. Research by Sanders and Alger and Alger completes the model I offer here. Whereas I have focused on the subjective presence of animals, these scholars illuminate intersubjectivity by documenting animals' ability to share intentions, feelings, and other mental states with their human companions. By interpreting the content of other minds-whether human or nonhuman-we develop a sense of self-in-relation. The selves of animals, evinced through agency, affectivity, coherence, and history, acquire another dimension through interaction that reveals their capacity to share thoughts and feelings. Although we humans can put our accounts of this experience into words, the capacity for intersubjectivity does not depend on language. Animals and people can share thoughts, intentions, and feelings, albeit at a less complex level than that which occurs between two people. 
The point of this article has been to show that there is something to animal selfhood and that this "something" becomes apparent during interaction. Our attributions of animals' selves are not merely wishful anthropomorphic projection. Because animals have agency and the other dimensions of the core self, they can choose courses of action that do not always coincide with our projections of what they "should" be like. Humans and animals can share meanings and emotions, but that does not imply that they always will share them. Nevertheless, in much of human-animal interaction, the features of agency, coherence, self-history, and affectivity coalesce, with memory helping to integrate them. Together, these give the animal an organizing, subjective perspective, or a core self, and concurrently make core Others available. Interactionist research offers a way to capture evidence of these features. Combined with critical anthropomorphism, interactionism allows us to recognize that animals' ways of being in the world are different, while it also honors those ways by attempting to understand them. To do so is to see animals differently, which is to see ourselves differently.

By expanding our field of vision in this way, the model of the self presented here has implications beyond the realm of human-animal interaction. In particular, the model extends interactionist possibilities past the limits of spoken language, opening up avenues of research on selfhood among "alingual" humans. Scholars have already broken ground in the case of the mentally disabled (Bogdan and Taylor 1989; Pollner and McDonald-Wikler 1985), Alzheimer's patients (Gubrium 1986), infants (Brazelton 1984; Stern 1985), deaf and blind children (Goode 1994), and autistic children (Rocque 2003). This literature concurs that those who provide care for people who have no capacity for verbal expression "literally 'do' the minds and selves of those who cannot speak" (Holstein and Gubrium 2000:152). For instance, Bogdan and Taylor explain how nondisabled family members assign personhood to the severely disabled. First, family members attribute thinking to the disabled person, granting him or her abilities to reason and understand. Consequently, the disabled person is considered a partner in interaction, with his or her gestures, body postures, and facial expressions doing what spoken language would otherwise have done. The disabled are seen as having preferences, feelings, and other characteristics that make us individuals. In addition, the disabled are incorporated into household routines and rituals, thus having their own places in the narrative history of the family. In this way, lived experience, which is at the heart of interactionism, provides the material through which the disabled attain the status of "person."

The relationship between selfhood and personhood has far-reaching implications. At the risk of raising questions I cannot answer, I will close with a controversy. Biologist Marc Bekoff (2002), renowned for his work on animal consciousness, emotions, and selfhood, captures the situation well. Marc's elderly mother has lost most of her cognitive, physiological, and locomotor capacities. She receives round-the-clock care. She does not recognize or even acknowledge Bekoff when he visits, and she manifests little if any awareness of her self, her surroundings, or her physical body. In short, she meets few of the criteria that we use to designate personhood. Yet few of us would deny that she has every right to be considered a person. In contrast, Bekoff points out that Jethro, his companion dog at the time, exhibited more of the qualities of personhood than his mother was able to. Jethro demonstrated the components of self that I have outlined here, but many people would nevertheless refuse to call Jethro a person, in any meaningful sense. To be sure, people who knew and loved Jethro granted him personhood, just as the dog owners in Sanders's (1999) study did for their canine companions. But apart from this circle of friends, the objections to doing so would be strong. Nonhuman beings who meet the criteria for personhood are simply not considered persons.

Expanding interactionism to acknowledge selfhood outside the realm of spoken language has tremendous consequences. The meaning of the self has not been established in stone. It remains fluid enough to allow for theoretical and conceptual surprises. And it will take theoretical and conceptual innovation to study it, no matter where it appears. 


\section{NOTES}

${ }^{1}$ The term "companion animal" is currently preferred over "pets," as "guardian" is preferable to "owner." Although birds, fish, rabbits, reptiles, and other species can also be companions, I focus on dogs and cats, which are numerically the most popular as well as those with which I am most familiar. For data on companion animals in American households, see AVMA 2002.

${ }^{2}$ Particularly helpful discussions of autoethnography appear in Wolcott 1999 and Goodall 2000.

3 "Agency" usually appears with its putative antithesis, "structure." This is an argument (in my view, an unnecessary one) about whether sociological (external) or psychological (internal) factors are more valuable for explaining human action. For a discussion of the history and a potential resolution of the debate, see Emirbayer and Mische 1998; see also Côté and Levine 2002; Rubenstein 2001.

${ }^{4}$ Although animals do not name one another, there is evidence that some species recognize other individuals' signature calls or whistles. See Masson and McCarthy 1995:36-37.

${ }^{5}$ To illustrate vitality affects, Stern (1985:56) offers the example of puppets, who "have little or no capacity to express categories of affect by way of facial signals, and their repertoire of conventionalized gestural or postural affect signals is usually impoverished. It is from the way they move in general that we infer the different vitality affects from the activation contours they trace. Most often, the characters of different puppets are largely defined in terms of particular vitality affects; one may be lethargic, with drooping limbs and hanging head, another forceful, and still another jaunty" (emphasis added).

${ }^{6}$ Victims of early childhood abuse offer other convincing evidence of preverbal memory. Although the child lacks words to describe what occurred, and perhaps cannot even recall distinctly, memories nevertheless endure.

\section{REFERENCES}

Adler, Patricia A. and Peter Adler. 1987. Membership Roles in Field Research. Newbury Park, CA: Sage.

Alger, Janet M. and Steven F. Alger. 1997. "Beyond Mead: Symbolic Interaction between Humans and Felines." Society \& Animals 5:65-81.

1999. "Cat Culture, Human Culture: An Ethnographic Study of a Cat Shelter." Society \& Animals 7:199-218.

- 2003. Cat Culture: The Social World of a Cat Shelter. Philadelphia: Temple University Press.

Allen, Colin and Marc Bekoff. 1997. Species of Mind: The Philosophy and Biology of Cognitive Ethology. Cambridge, MA: MIT Press.

American Veterinary Medical Association (AVMA). 2002. U. S. Pet Ownership \& Demographics Sourcebook. Schaumburg, IL: AVMA.

Arluke, Arnold and Clinton R. Sanders. 1996. Regarding Animals. Philadelphia: Temple University Press.

Becker, Howard and Blanche Geer. 1960. "The Analysis of Qualitative Field Data." Pp. 652-60 in Human Organization Research, edited by R. Adams and J. Preiss. Homewood, IL: Dorsey. 
Bekoff, Marc, ed. 2000. The Smile of a Dolphin: Remarkable Accounts of Animal Emotions. New York: Random House/Discovery.

—. 2002. Minding Animals: Awareness, Emotions, and Heart. Oxford: Oxford University Press.

Bogdan, Robert and Steven Taylor. 1989. "Relationships with Severely Disabled People: The Social Construction of Humanness." Social Problems 36:135-48.

Bonner, J. T. 1980. The Evolution of Culture in Animals. Princeton, NJ: Princeton University Press.

Brazelton, T. Berry. 1984. "Four Stages in the Development of Mother-Infant Interaction." Pp. 19-34 in The Growing Child in Family and Society, edited by N. Kobayashi and T. B. Brazelton. Tokyo: University of Tokyo Press.

Bruner, Jerome and David A. Kalmar. 1998. "Narrative and Metanarrative in the Construction of Self." Pp. 308-31 in Self-Awareness: Its Nature and Development, edited by M. Ferrari and R. J. Sternberg. New York: Guilford.

Burghardt, Gordon M. 1998. "The Evolutionary Origins of Play Revisited: Lessons from Turtles." Pp. 1-26 in Animal Play: Evolutionary, Comparative, and Ecological Perspectives, edited by M. Bekoff and J. Byers. Cambridge: Cambridge University Press.

Charmaz, Kathy. 1983. "The Grounded Theory Method: An Explication and Interpretation." Pp. 102-26 in Contemporary Field Research: A Collection of Readings, edited by R. M. Emerson. Boston: Little, Brown.

Cooley, Charles Horton. [1902] 1964. Human Nature and the Social Order. New York: Schocken.

Côté, James E. and Charles G. Levine. 2002. Identity Formation, Agency, and Culture: A Social Psychological Synthesis. Mahwah, NJ: Erlbaum.

Crist, Eileen. 1999. Images of Animals: Anthropomorphism and Animal Mind. Philadelphia: Temple University Press.

Darwin, Charles. [1872] 1998. The Expression of the Emotions in Man and Animals. 3d ed. New York: Oxford University Press.

Dawkins, Marian Stamp. 1998. Through Our Eyes Only? The Search for Animal Consciousness. Oxford: Oxford University Press.

Denzin, Norman. 1989. Interpretive Biography. Newbury Park, CA: Sage.

Ellis, Carolyn. 1991. "Sociological Introspection and Emotional Experience." Symbolic Interaction 14:2350.

—. 1997. "Evocative Autoethnography: Writing Emotionally about Our Lives." Pp. 115-39 in Representation and the Text: Re-framing the Narrative Voice, edited by W. G. Tierney and Y. S. Lincoln. Albany: State University of New York Press.

—. 1998. "I Hate My Voice': Coming to Terms with Minor Bodily Stigmas." Sociological Quarterly 39:517-37. 
Emirbayer, Mustafa and Ann Mische, 1998. "What Is Agency?" American Journal of Sociology 103:9621023.

Fisher, John Andrew. 1991. "Disambiguating Anthropomorphism: An Interdisciplinary Review." Pp. 49-85 in Perspectives in Ethology, vol. 9: Human Understanding and Animal Awareness, edited by P. Bateson and P. Klopfer. New York: Plenum.

Glaser, Barney. 1978. Theoretical Sensitivity. Mill Valley, CA: Sociology Press.

Glaser, Barney G. and Anselm L. Strauss. 1967. The Discovery of Grounded Theory. Chicago: Aldine.

Goffman, Erving. 1959. The Presentation of Self in Everyday Life. Garden City, NY: Anchor Books.

Goodall, H. L., Jr. 2000. Writing the New Ethnography. Lanham, MD: AltaMira.

Goodall, Jane. 1990. Through a Window: My Thirty Years with the Chimpanzees of Gombe. Boston: Houghton Mifflin.

Goode, David. 1994. World without Words: The Social Construction of Children Born Deaf and Blind. Philadelphia: Temple University Press.

Gubrium, Jaber. 1986. "The Social Preservation of Mind: The Alzheimer's Disease Experience." Symbolic Interaction 6:37-51.

Hayano, David. 1979. "Auto-Ethnography: Paradigms, Problems, and Prospects." Human Organization 38:99-104.

Hewitt, John P. 2000. Self and Society: A Symbolic Interactionist Social Psychology. 8th ed. Needham Heights, MA: Allyn and Bacon.

Holstein, James A. and Jaber F. Gubrium. 2000. The Self We Live By: Narrative Identity in a Postmodern World. Oxford: Oxford University Press.

Irvine, Leslie. 1999. Codependent Forevermore: The Invention of Self in a Twelve Step Group. Chicago: University of Chicago Press.

—_. Forthcoming. If You Tame Me: Understanding Our Connection with Animals. Philadelphia: Temple University Press.

James, William. [1890] 1950. The Principles of Psychology. New York: Dover.

—. [1892] 1961. Psychology: The Briefer Course. New York: Harper.

Lerman, Rhoda. 1996. In the Company of Newfs. New York: Henry Holt.

Masson, Jeffrey Moussaieff. 1997. Dogs Never Lie about Love: Reflections on the Emotional World of Dogs. New York: Three Rivers/Crown.

Masson, Jeffrey Moussaieff and Susan McCarthy. 1995. When Elephants Weep: The Emotional Lives of Animals. New York: Delta.

Mead, George Herbert. [1934] 1962. Mind, Self and Society. Chicago: University of Chicago Press. 
Messent, Peter. 1983. "Social Facilitation of Contact with Other People by Pet Dogs." Pp. 37-46 in New Perspectives on Our Lives with Companion Animals, edited by A. Katcher and A. Beck. Philadelphia: University of Pennsylvania Press.

Mitchell, Robert W., Nicholas S. Thompson, and H. Lyn Miles, eds. 1997. Anthropomorphism, Anecdotes, and Animals. Albany: State University of New York Press.

Myers, Gene. 1998. Children and Animals: Social Development and Our Connections to Other Species. Boulder, CO: Westview Press.

Patterson, Francine and Eugene Linden. 1981. The Education of Koko. New York: Holt, Rinehart and Winston.

Pepperberg, Irene. 1991. "A Communicative Approach to Animal Cognition: A Study of Conceptual Abilities of an African Grey Parrot." Pp. 153-86 in Cognitive Ethology: The Minds of Other Animals, edited by C. A. Ristau. Hillsdale, NJ: Lawrence Erlbaum.

Phillips, Mary T. 1994. "Proper Names and the Social Construction of Biography: The Negative Case of Laboratory Animals." Qualitative Sociology 17:119-42.

Pollner, Melvin and Lynn McDonald-Wikler. 1985. "The Social Construction of Unreality: A Case Study of a Family's Attribution of Competence to a Severely Retarded Child.” Family Process 24:241-54.

Rambo Ronai, Carol. 1992. "The Reflexive Self through Narrative: A Night in the Life of an Erotic Dancer/Researcher." Pp. 102-24 in Investigating Subjectivity: Research on Lived Experience, edited by C. Ellis and M. Flaherty. Newbury Park, CA: Sage.

— 1996. "Multiple Reflections of Child Sex Abuse: An Argument for a Layered Account." Pp. 24-43 in Private Sociology: Unsparing Reflections, Uncommon Gains, edited by A. B. Shostak. Dix Hills, NY: General Hall.

Rocque, William. 2003. "Body Talk: Identity and Narratives of Self in Families with Autistic Members." Unpublished manuscript.

Rubenstein, David. 2001. Culture, Structure, and Agency: Toward a Truly Multidimensional Sociology. Thousand Oaks, CA: Sage.

Sanders, Clinton R. 1990. "Excusing Tactics: Social Responses to the Public Misbehavior of Companion Animals." Anthrozoös 4:82-90.

— 1991. "The Animal 'Other': Self-Definition, Social Identity, and Companion Animals." Pp. 662-68 in Advances in Consumer Research, vol. 17, edited by M. Goldberg et al. Provo, UT: Association for Consumer Research.

—. 1993. "Understanding Dogs: Caretakers' Attributions of Mindedness in Canine-Human Relationships." Journal of Contemporary Ethnography 22:205-26.

_ 1999. Understanding Dogs: Living and Working with Canine Companions. Philadelphia: Temple University Press.

. 2000. "The Impact of Guide Dogs on the Identity of People with Visual Impairments." Anthrozoös 13:131-39. 
Sanders, Clinton R. and Arnold Arluke. 1993. "If Lions Could Speak: Investigating the Animal-Human Relationship and the Perspectives of Nonhuman Others. Sociological Quarterly 34:377-90.

Shapiro, Kenneth J. 1990. "Understanding Dogs through Kinesthetic Empathy, Social Construction, and History." Anthrozoös 3:184-95.

- 1997. "A Phenomenological Approach to the Study of Nonhuman Animals." Pp. 277-95 in Anthropomorphism, Anecdotes, and Animals, edited by R. Mitchell, N. Thompson, and H. Miles. Albany: State University of New York Press.

Stern, Daniel N. 1985. The Interpersonal World of the Infant: A View from Psychoanalysis and Developmental Psychology. New York: Basic Books.

Stewart, Alex. 1998. The Ethnographer's Method. Thousand, Oaks CA: Sage.

Strauss, Anselm, ed. 1964. George Herbert Mead on Social Psychology. Chicago: University of Chicago Press.

Strauss, Anselm and Juliet Corbin, eds. 1997. Grounded Theory in Practice. Thousand Oaks, CA: Sage.

Tabor, Roger. 1983. The Wild Life of the Domestic Cat. London: Arrow Books.

Thomas, Elizabeth Marshall. 1993. The Hidden Life of Dogs. New York: Houghton Mifflin.

— 1994. The Tribe of Tiger: Cats and Their Culture. New York: Simon \& Schuster.

- 2000. The Social Lives of Dogs: The Grace of Canine Company. New York: Simon \& Schuster.

Weber, Max. 1949. The Methodology of the Social Sciences. Edited by H. H. Gerth and C. W. Mills. Glencoe, IL: Free Press.

Wolcott, Harry F. 1999. Ethnography: A Way of Seeing. Walnut Creek, CA: AltaMira. 